\title{
Insights on Foam Transport from a Texture-Implicit Local-Equilibrium Model with an Improved Parameter Estimation Algorithm
}

\author{
Yongchao Zeng ${ }^{\dagger}$, Aarthi Muthuswamy ${ }^{\dagger}$, Kun Ma $^{\dagger \xi}$, Le Wang ${ }^{\dagger}$, Rouhi Farajzadeh $^{\ddagger}$, Maura \\ Puerto $^{\dagger}$, Sebastien Vincent-Bonnieu ${ }^{\ddagger}$, Ali Akbar Eftekhari ${ }^{\perp}$, Ying Wang ${ }^{\dagger}$, Chang Da ${ }^{\dagger}$, Jeffrey C. \\ Joyce ${ }^{\dagger}$, Sibani L. Biswal ${ }^{\dagger *}$, and George J. Hirasaki ${ }^{\dagger *}$
}

${ }^{\dagger}$ Rice University, 6100 Main St., MS-362, Department of Chemical and Biomolecular Engineering, Houston, TX, 77005 USA.

†Shell Global Solutions International, 2288 GS Rijswijk, the Netherlands

${ }^{\perp}$ Delft University of Technology, Delft, 2628 CN, the Netherlands

${ }^{\complement}$ Current address: Total E\&P Research and Technology USA, LLC, 1201 Louisiana Street, Houston, TX, 77002 USA

KEYWORDS: Foam Simulation, Texture-Implicit, Local Equilibrium Model, Population Balance Model, Gas Mobility Control, Enhanced Oil Recovery (EOR)

*To whom correspondence should be addressed: email: biswal@rice.edu, gjh@rice.edu 
ABSTRACT: We present an insightful discussion on the implications of foam transport inside porous media based on an improved algorithm for the estimation of model parameters. A widely used texture-implicit local-equilibrium foam model, STARS ${ }^{\mathrm{TM}}$, is used to describe the reduction of gas mobility in the state of foam with respect to free gas. Both the dry-out effect and sheardependent rheology are considered in foam simulations. We estimate the limiting capillary pressure $P_{c}^{*}$ from $f m d r y$ values in the STARS ${ }^{\mathrm{TM}}$ model to characterize foam film stability in a dynamic flowing system. We find that $P_{c}^{*}$ is a good indicator of foam strength in porous media and varies with different gas types. We also calculate $P_{c}^{*}$ for different foaming surfactants and find that foam stability is correlated with the Gibbs surface excess concentration. We compare our improved parameter estimation algorithm with others reported in literature. The robustness of the algorithm is validated for various foam systems. 


\section{Introduction}

Foam is the dispersion of discontinuous gas in liquid ${ }^{1}$ and is used in a variety of subsurface applications. For example, foam can be used to remediate non-aqueous phase liquid (NAPL)-contaminated aquifers ${ }^{2}$ and to control the mobility and conformance of injected fluids in enhanced oil recovery (EOR) ${ }^{3-8}$ processes. Additionally, foam can be injected as a novel energized fluid for hydraulic fracturing ${ }^{9-11}$. If properly designed, foam can simultaneously address viscous fingering, gravity override and reservoir heterogeneity, which are three major issues that greatly limit the sweep efficiency of gas or the water-alternating-gas (WAG) injection process ${ }^{12-15}$. A number of successful foam pilot tests have been reported in the literature ${ }^{3,7,16-20}$. However, what remains less well understood is how to better model foam transport in porous media ${ }^{21,22}$.

Depending on whether the local bubble density (or namely foam texture) $n_{f}$ is explicitly expressed, current foam transport models can be categorized into two different groups $^{1,13,21-24}$ : texture-explicit population balance models and texture-implicit localequilibrium models. The first approach requires not only an additional partial differential equation (PDE) for bubble transport but also exact expressions for bubble generation and destruction terms. The second approach uses only an empirical algebraic formula to correlate the gas mobility reduction as a function of a series of local conditions, such as surfactant concentration, water saturation, shear rate and oil saturation. We believe the implicit-texture local-equilibrium approach is more promising for field-scale applications for the following reasons: (a) the physical foam dynamic mechanisms are complex in the mechanistic explicit-texture population-balance model and the model parameters are 
often difficult to extract from core-flood experiments; (b) an additional PDE for bubble transport in the population-balance model would significantly increase the computational time required to execute the calculations compared to an algebraic expression as in the texture-implicit local-equilibrium model, and (c) both implicit-texture and population balance models can match the steady-state experimental data equally well. Therefore, we model foam transport in this paper using STARS ${ }^{\mathrm{TM}}$, a commercially available implicittexture local-equilibrium foam model, and discuss insightful implications based on the parameters estimated using our improved algorithm.

A proper method to extract values for all the parameters to fit lab-scale experiments is needed with a well-defined foam model. Different algorithms have been proposed in the literature to estimate STARS ${ }^{\mathrm{TM}}$ foam model parameters. Ma et al. ${ }^{25}$ developed a method to estimate the parameters describing water-saturation dependence and successfully modeled the dry-out effect. However, Ma et al. ${ }^{25}$ required an extra transient experiment where gas is constantly injected into a core $100 \%$ saturated with surfactant solution in addition to steady-state foam data. They also came across the issue of non-uniqueness and realized that two different solutions matched the experimental data based on the initial inputs for the model parameters. Additionally, the maximum apparent viscosity data must be determined precisely in the experiment to locate the transition point between high- and low-quality regimes. Boeije et al. ${ }^{12}$ proposed another method in which five parameters can be extracted simply and simultaneously from steady-state data using just a pencil and a calculator. The method can quickly provide initial estimates to least square fitted values later determined using a computer. However, strong assumptions are made without adequate evidence and justification. For example, the parameter epdry, which is 
defined as a measure of how abruptly the foam collapses at a given limiting water saturation, is arbitrarily assigned to large values. However, whether foam experiences such abrupt coalescence in all cases remains an open question. Additionally, Newtonian rheology is assumed valid for foam in the high-quality regime, which may be inconsistent with the experimental results reported in literature ${ }^{26}$.

We propose an improved algorithm to estimate STARS $^{\mathrm{TM}}$ foam model parameters. Both the water-saturation dependence and shear-rate dependence are considered. We illustrate how this improved algorithm can be used to estimate five parameters in the water-saturation and shear-rate dependent functions, respectively. The insights gained regarding foam transport from the parameters estimated using our new algorithm allows for better design of flow through porous media.

\section{Theory}

\subsection{Foam Dynamics in Porous Media}

In the presence of foaming agents, such as surfactants or nano-particles ${ }^{27}$, bubbles can be generated inside porous media through different mechanisms ${ }^{1,28,29}$, such as snap-off, lamella division, leave-behind and neighbor-induced pinch-off. Snap-off is a foam generation mechanism in heterogeneous porous media during a major permeability increase in the direction of flow ${ }^{30}$. When the gas thread flows from a constricted pore-throat to a relatively expanded pore space, the reduced curvature at the gas front induces accumulation of the liquid phase back-flow in the pore neck and restricts the non-wetting gas phase ${ }^{31}$. Lamella division is a secondary generation mechanism and a major foam generation mechanism in homogeneous porous media. When a relatively large bubble approaches a branching point, the lamella may split 
into two and flow into different channels downstream. A pressure difference across the foam film must overcome a yield pressure to counterbalance the capillary resistance and mobilize the lamella through the pore structures for lamella division to occur $^{32}$. A minimum pressure gradient (MPG) exists on the macroscopic scale, above which lamella mobilization and division can form a strong foam. Foam is generated primarily by leave-behind when the pressure gradient is below the MPG. The liquid may be sandwiched by the invading gas during the liquid drainage process and squeezed into a thin lamella connecting two grains in the pore structure. Lamellae generated by leave-behind are parallel to the direction of flow and thus contribute less flow resistance compared to those generated by snap-off and lamella division. Neighbor-induced pinch-off is a recent mechanism proposed for foam generation mechanism in porous media where bubbles can be shear-thinned and pinched by adjacent bubbles to generate new lamella when flowing through pore constrictions.

Foam bubbles are thermodynamically unstable and experience constant coalescence because of capillary suction, gas diffusion, thickness fluctuation, etc. A pressure difference between the gas and liquid known as capillary pressure $P_{c}$ occurs to the curved interface. The capillary pressure drives the liquid to plateau borders and their junctions. Therefore, the $P_{c}$ drains the liquid content between two gas phases and can rupture the thin film. Another foam coalescence mechanism is Oswald ripening resulting from gas diffusion between bubbles of different sizes. Smaller bubbles are ultimately absorbed into larger neighboring bubbles by this thermodynamically driven process because of the pressure difference, or more precisely, the chemical potential of the gas in the different-sized bubbles. It has been well recognized that gas 
diffusion plays a major role in the bulk foam destruction process ${ }^{33}$. However, whether gas diffusion is a pronounced factor responsible for foam coalescence in porous media remains controversial in the literature. Nonnekes et al. ${ }^{34}$ argued that for bubbles greater than the pore size, which is the case for in-situ-generated foam, gas diffusion does not generate a coarse bubble size distribution. A third foam coalescence mechanism is film thickness fluctuation. Lamellae cannot survive either mechanical- or thermal-driven fluctuations with wavelengths greater than a critical value ${ }^{35}$.

A steady state is reached when the rate of bubble generation is in equilibrium with the rate of bubble coalescence during the dynamic process of gas and liquid simultaneous flow. We introduce the apparent viscosity $\mu_{\text {app }}$ as a measure of foam strength to quantify the flow resistance in porous media, which is defined as the pressure gradient $\nabla p$ normalized by rock permeability $k_{\text {rock }}$ and total superficial velocity $u_{t}$. We measure the steady-state pressure drop $\Delta p$ across a core with length $L$ at different gas and liquid flow rates $u_{g}$ and $u_{w}$ and calculate the apparent viscosity, as shown in Equation 1.

$$
\mu_{\text {app }}=-\frac{k_{\text {rock }} \nabla p}{u_{t}}=\frac{k_{\text {rock }} \Delta p}{\left(u_{w}+u_{g}\right) \cdot L}
$$

Although we introduced apparent viscosity $\mu_{a p p}$ to quantify foam strength, foam in porous media is modeled as a two-phase flow instead of single-phase because gas and liquid are transported at different velocities ${ }^{21,36}$. Phase separation occurs in the presence of permeability contrast ${ }^{29,37}$. Gas mobility can be reduced by several orders 
of magnitude in the state of foam, whereas the liquid mobility for a given water saturation changes negligibly ${ }^{22,38}$. Bernard et al. ${ }^{39}$ rationalized that the gas flow path is blocked by lamellae, whereas most water remains in small pores and in proximity to the solid surfaces as the wetting phase. Specifically, gas mobility in the state of foam is reduced by two mechanisms ${ }^{1}$ : first, the stationary or trapped gas decreases the cross-sectional area that gas can flow through, decreasing the relative permeability; second, the capillary resistance increased within blocked lamella must be forced to allow the discontinuous gas to flow, and therefore the effective viscosity of gas increases. The two mechanisms can be independently considered ${ }^{1,23}$ or combined into a single variable for the foam flow simulation ${ }^{25,38}$.

Foam experiences major coalescence at the limiting capillary pressure $P_{c}^{*}$ when the disjoining pressure can no longer prevent the lamella from rupturing ${ }^{40}$. This dry-out effect occurs at a given limiting water saturation $S_{w}^{*}$ when the foam quality $f_{g}$ is $\mathrm{high}^{25,41}$. Foam quality in porous media is defined as the gas fractional flow as shown in Equation 2 and is a critical operation condition in the foam process. Operation at higher foam quality can reduce the cost of the expensive surfactant. However, a high foam quality $f_{g}$ significantly reduces the foam apparent viscosity, and therefore gas mobility control is lost. As gas fractional flow is increased, the foam dries out and the water saturation approaches a value $S_{w}^{*}$ at which the foam coalesces at increasing rate. The limiting water saturation $S_{w}^{*}$ can be systematically estimated using our new algorithm by conducting quality-scan experiments where total velocity is held constant and the flow resistance is in a steady-state. $S_{w}^{*}$ is believed to be dependent on a variety of factors, such as surfactant, electrolyte, gas type, oil saturation and rock 
properties. The corresponding $P_{c}^{*}$ is also a dynamic property determined both by the system and operating conditions ${ }^{41}$.

$$
f_{g}=\frac{u_{g}}{u_{t}}=\frac{u_{g}}{u_{g}+u_{w}}
$$

Equation 2

Another important feature of foam flow in porous media is its shear-dependent rheology. Foam strength might be completely different in the near-wellbore region than in the far-field region due to its decelerating propagating velocity ${ }^{42}$. A mathematical model computing foam bubbles flowing in smooth capillary bundles has been well developed in the literature ${ }^{43,44}$. Calculations agree with experimental observations that foam is a shear thinning fluid in a capillary tube, and the effective gas viscosity is inversely proportional to the bubble velocity raised to the minus onethird power. However, the real subsurface micro-structure is more complicated than the smooth capillary bundles. Lab observations indicate that foam can be either shearthinning or shear-thickening under different conditions. Thus we simply correlate the shear-rate dependence with total velocity or the capillary number raised to an adjustable power.

\subsection{STARS ${ }^{\mathrm{TM}}$ Foam Model}

STARS $^{\mathrm{TM}}$ is commercially available reservoir simulator including a textureimplicit local-equilibrium foam model in which the gas relative permeability in the

presence of foam $k_{r g}^{f}$ is modified by multiplying the gas relative permeability without 
foam $k_{r g}^{n f}$ at a given water saturation with a mobility reduction factor $F M$, as shown in Equation 3.

$$
k_{r g}^{f}=k_{r g}^{n f} \times F M
$$

FM is inversely related to the product of different functions as shown in Equation 4. These functions account for the foam dependencies on different factors, such as surfactant concentration, water saturation, shear-rate, etc.

$$
F M=\frac{1}{1+f m m o b \times \prod_{i=1}^{n} F_{i}}
$$

Equation 4

The fmmob parameter refers to the maximum gas mobility reduction that can be achieved. $F_{i}$ are different functions of dependences ranging from 0 to 1 . When all $F_{i}$ are equal to 1 , foam obtains its maximum strength. A full description of the STARS $^{\text {TM }}$ foam model can be found in the literature ${ }^{13,21,36}$. This work only considers foam dependences on water saturation $\left(F_{\text {water }}\right)$ and shear rate $\left(F_{\text {shear }}\right)$. Consequently, Equation 4 is reduced to

$$
F M=\frac{1}{1+f m m o b \times F_{\text {water }} \times F_{\text {shear }}}
$$


$F_{\text {water }}$ is the water-saturation dependence, which is the inverse tangent function of water saturation $S_{w} \cdot F_{\text {water }}$ is a continuous and monotonically increasing function of water saturation $S_{w}$, as shown in Equation 6 , and decreases significantly as water saturation $S_{w}$ decreases across the limiting water saturation $S_{w}^{*}$.

$$
F_{\text {water }}=0.5+\frac{\arctan \left[\operatorname{epdry}\left(S_{w}-f m d r y\right)\right]}{\pi}
$$

Equation 6

$F_{w a t e r}$ contains two parameters: $f m d r y$ and epdry. fmdry corresponds to the limiting water saturation $S_{w}^{*}$, at which foam begins experiencing significant coarsening and drying and should be in the range of connate water saturation $S_{w c}$ and $\left(1-S_{g r}\right)$. As previously described, epdry controls the collapse rate of foam. A large epdry value indicates that foam dries out sharply, whereas small epdry indicates that foam dries out more gradually.

$F_{\text {shear }}$ is the shear-rate dependence, which is a function of the local capillary number $N_{C a}$, as shown in Equation 7.

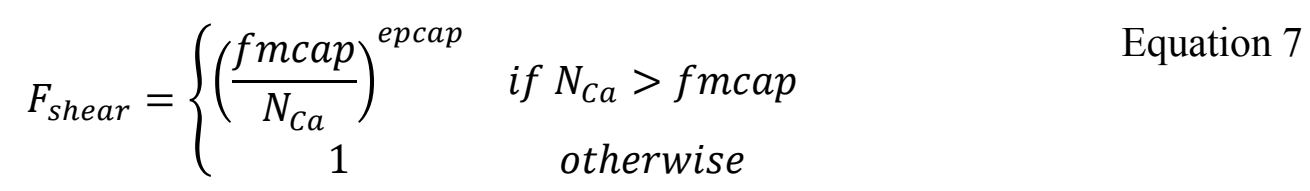

The adjustable parameter epcap determines how foam rheology is dependent on shear-rate. A positive epcap corresponds to shear-thinning rheology. fmcap is a parameter with which to normalize $F_{\text {shear }}$, given the constraints that all $F_{i}$ functions should fall within the interval of $[0,1]$. 
Capillary number $N_{C a}$ is a dimensionless number in fluid mechanics, which characterizes the relative effect between viscous and capillary forces. The local capillary number is an indicator of the viscous shear rate of the system. The higher capillary number corresponds to a greater viscous shear stress. However, the most appropriate expression for local capillary number remains controversial in the literature ${ }^{12,26,36}$. At least three methods exist to define $N_{C a}$, as shown in Equations 810 , where $k$ is the rock permeability, $\nabla p$ is the local pressure gradient, and $\sigma$ is the surface tension between the gaseous and aqueous phases.

$$
\begin{aligned}
& N_{C a}=\frac{-k \nabla p}{\sigma}=\frac{\mu_{a p p} \times u_{t}}{\sigma} \\
& N_{C a}=\frac{\mu_{w} \times u_{g}}{\sigma} \\
& N_{C a}=\frac{\mu_{w} \times u_{t}}{\sigma}
\end{aligned}
$$

Equation 10

Boeije et al. ${ }^{12}$ suggested that Equation 8 defines the local capillary number because it is consistent with its original definition in two-phase flow, where the wetting fluid displaces the trapped non-wetting glob. Including $F_{\text {shear }}$ in the STARS ${ }^{\mathrm{TM}}$ model with this capillary number definition could improve the data fit in the quality-scan experiment as described in Boeije et al. ${ }^{12}$. However, this definition would increase the computational cost by implicitly defining the mobility reduction factor $F M$ and requiring iteration for convergence. 
Abbaszadeh et al. ${ }^{36}$ used the second definition as shown in Equation 9 because the shear thinning rheology of foam in a capillary bundle scales with the gas bubble velocity. However, $u_{g}$ may not scale well with the shear rate in porous media because a large fraction of gas is trapped in real rock $^{39}$; thus, the bubble velocity deviates significantly from $u_{g}$. Additionally, such a definition would complicate $F_{\text {water }}$ and $F_{\text {shear }}$ by introducing shear-rate dependency in quality-scan experiment and thus complicates the parameter estimation.

The effects of $u_{g}$ and $u_{w}$ on the shear-rate on the foam in rock are difficult to quantify. Hence, we simply find their sum and scale the shear rate in porous media with total superficial velocity $u_{t}$ whereby Equation 10 defines the local capillary number. We will demonstrate in section 4 that our algorithm provides an acceptable fit to the experimental data in a series of varied foam systems. In particular, sections 4.1 and 4.2 will illustrate that it is easy to reduce the five-parameter estimation into two simple tasks with such a definition. We first estimate three parameters ( fmmob, epdry, and fmdry) from the quality-scan experiment. Second, we estimate the other two parameters (epcap and fmcap) from the flow-rate-scan experiment.

\section{Materials and Methods}

We investigate different foam systems with various surfactant formulation, gas types, etc. Gas was co-injected with surfactant solution in all cases, as shown in Figure 1. The pressure drop $\Delta p$ at steady state along the core sample was recorded as a function of the gas and liquid velocities. The apparent viscosity $\mu_{a p p}$ was then calculated using Equation 1. The studied systems are listed in Table 1. System A is a demonstration case with which 
we will compare our improved algorithm to estimate STARS ${ }^{\mathrm{TM}}$ model parameters in sections 4.1 and 4.2. We examine the effect of different gas types on foam strength in system B and correlate foam strength with lamella stability. We compare the foamability of the anionic surfactant, $\mathrm{C}_{14-16}$ alpha olefin sulfonate (AOS1416, from Stepan) in system C with two different zwitterionic surfactants lauryl betaine (LB, from Solvay Mackam Lab) and lauryl sultaine (LS, from Solvay Mackam Lab), which are typically used as foam boosters in presence of crude oil ${ }^{45}$. The surfactants listed are used without further treatment. Synthetic seawater was made with salts (from Sigma Aldrich) of approximately $0.67 \mathrm{~g} / \mathrm{L} \mathrm{KCl}, 10.15 \mathrm{~g} / \mathrm{L} \mathrm{MgCl}_{2} \cdot 6 \mathrm{H}_{2} \mathrm{O}, 1.47 \mathrm{~g} / \mathrm{L} \mathrm{CaCl}{ }_{2} \cdot 2 \mathrm{H}_{2} \mathrm{O}, 3.83 \mathrm{~g} / \mathrm{L}$ $\mathrm{Na}_{2} \mathrm{SO}_{4}$, and $25.21 \mathrm{~g} / \mathrm{L} \mathrm{NaCl}$.

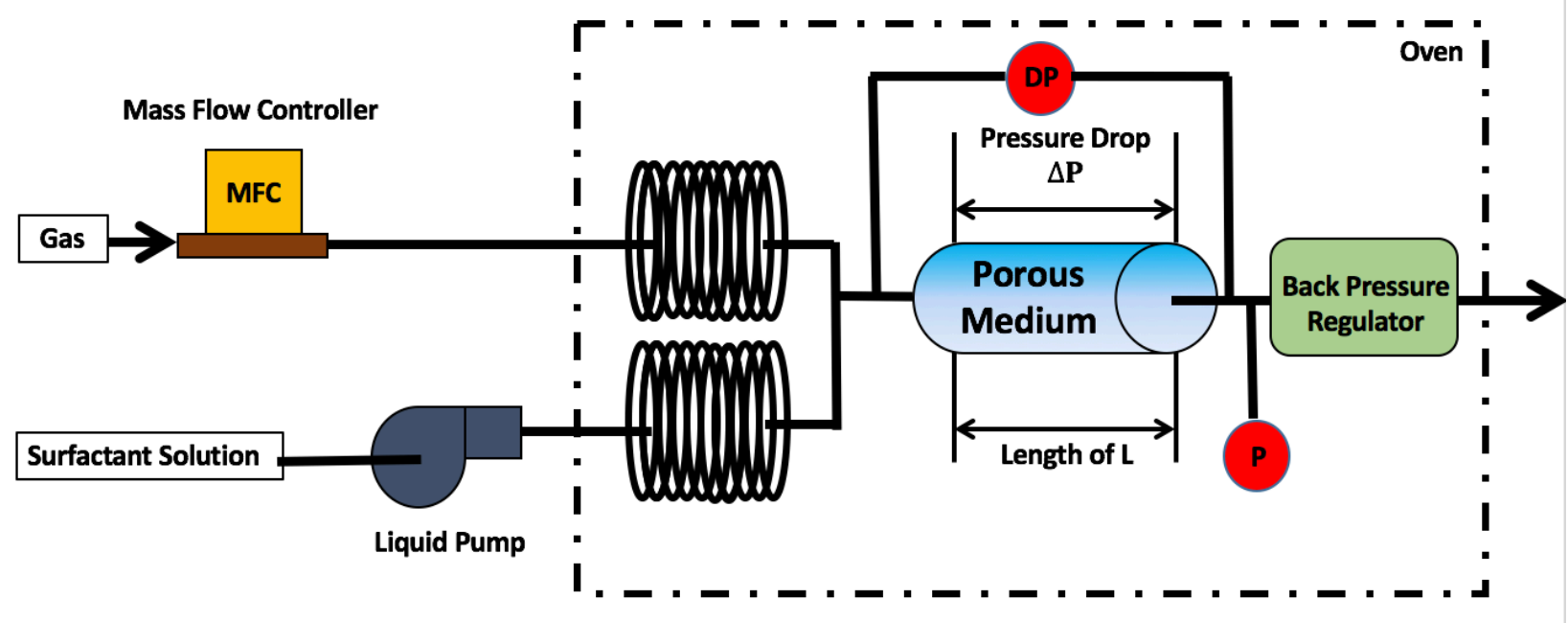

Figure 1: Schematic of foam flood experimental setup used to determine the dynamics of foam transport. 
Table 1: Foam flood systems examined in this study

\begin{tabular}{|c|c|c|c|c|c|c|}
\hline System & $\begin{array}{l}\text { Porous } \\
\text { Medium }\end{array}$ & Surfactant Formulation & Gas & Brine & $\begin{array}{c}\text { Flow } \\
\text { rate } \\
\text { (Quality-scan) } \\
\text { (ft/day) }\end{array}$ & $\begin{array}{c}\text { Temperature } \\
\left({ }^{\circ} \mathrm{C}\right)\end{array}$ \\
\hline A & $\begin{array}{l}\text { Bentheimer } \\
\text { (0.65 Darcy) }\end{array}$ & $0.15 \mathrm{wt} \%$ AOS1416 and $0.35 \mathrm{wt} \%$ LB Blend & $\mathrm{N}_{2}$ & $\begin{array}{r}\text { Sea } \\
\text { Water }\end{array}$ & 4.2 & 45 \\
\hline B & $\begin{array}{l}\text { Bentheimer } \\
\text { (2.30 Darcy) }\end{array}$ & $1 \mathrm{wt} \%$ AOS1416 & $\begin{array}{c}\mathrm{N}_{2} \\
\mathrm{CH}_{4} \\
\mathrm{CO}_{2}\end{array}$ & $\begin{array}{r}\text { Sea } \\
\text { Water }\end{array}$ & 4 & Ambient \\
\hline $\mathrm{C}$ & $\begin{array}{l}\text { Bentheimer } \\
\text { (2.70 Darcy) } \\
\text { Bentheimer } \\
\text { (2.50 Darcy) } \\
\text { Bentheimer } \\
\text { (2.52 Darcy) }\end{array}$ & $0.5 \mathrm{wt} \%$ AOS1416 & $\mathrm{N}_{2}$ & $\begin{array}{r}\text { Sea } \\
\text { Water }\end{array}$ & 4 & 45 \\
\hline
\end{tabular}

Two major foam experiments are primarily conducted in the literature to assess foam properties: a quality-scan experiment and a flow-rate-scan experiment. The total flow rate is constant in the quality-scan experiment so that the pressure decrease across the porous medium is measured as a function of foam quality $f_{g}$. The foam quality is fixed, while the total flow rate (or superficial velocity $u_{t}$ ) is varied in the flow-rate-scan experiment. 
We utilize the Corey relative permeability model for our two-phase (gaseous and aqueous) flow in absence of a surfactant, as shown in Equations 11 and 12, where $k_{r w}^{o}$ and $k_{r g}^{o}$ are the end-point relative permeability for water and gas, respectively, $S_{w c}$ is connate water saturation, $S_{g r}$ is residual gas saturation, and $n_{w}$ and $n_{g}$ are the Corey exponents for water and gas, respectively. The relative permeability data for Bentheimer sandstone found in the literature is listed in Supporting Information Table S1.

$$
\begin{aligned}
& k_{r w}=k_{r w}^{o} \times\left(\frac{S_{w}-S_{w c}}{1-S_{w c}-S_{g r}}\right)^{n_{w}} \\
& k_{r g}^{n f}=k_{r g}^{o} \times\left(\frac{S_{g}-S_{g r}}{1-S_{w c}-S_{g r}}\right)^{n_{g}}
\end{aligned}
$$

Equation 12

\section{Results and Discussion}

We will first demonstrate our algorithm to estimate foam parameters to fit both quality and flow-rate scan experiments for a particular gas-surfactant system. Then in section 4.3, we will provide insights on the role of gas type as well as surfactant structures on steady state foam strength in porous media based on the parameters we extract from STARS ${ }^{\mathrm{TM}}$ model for various systems.

In System A, $\mathrm{N}_{2}$ and an AOS1416/LB surfactant blend were co-injected into a 6.7-inch Bentheimer sandstone core. Both the quality-scan and flow-rate-scan experimental results are shown in Figure 2 

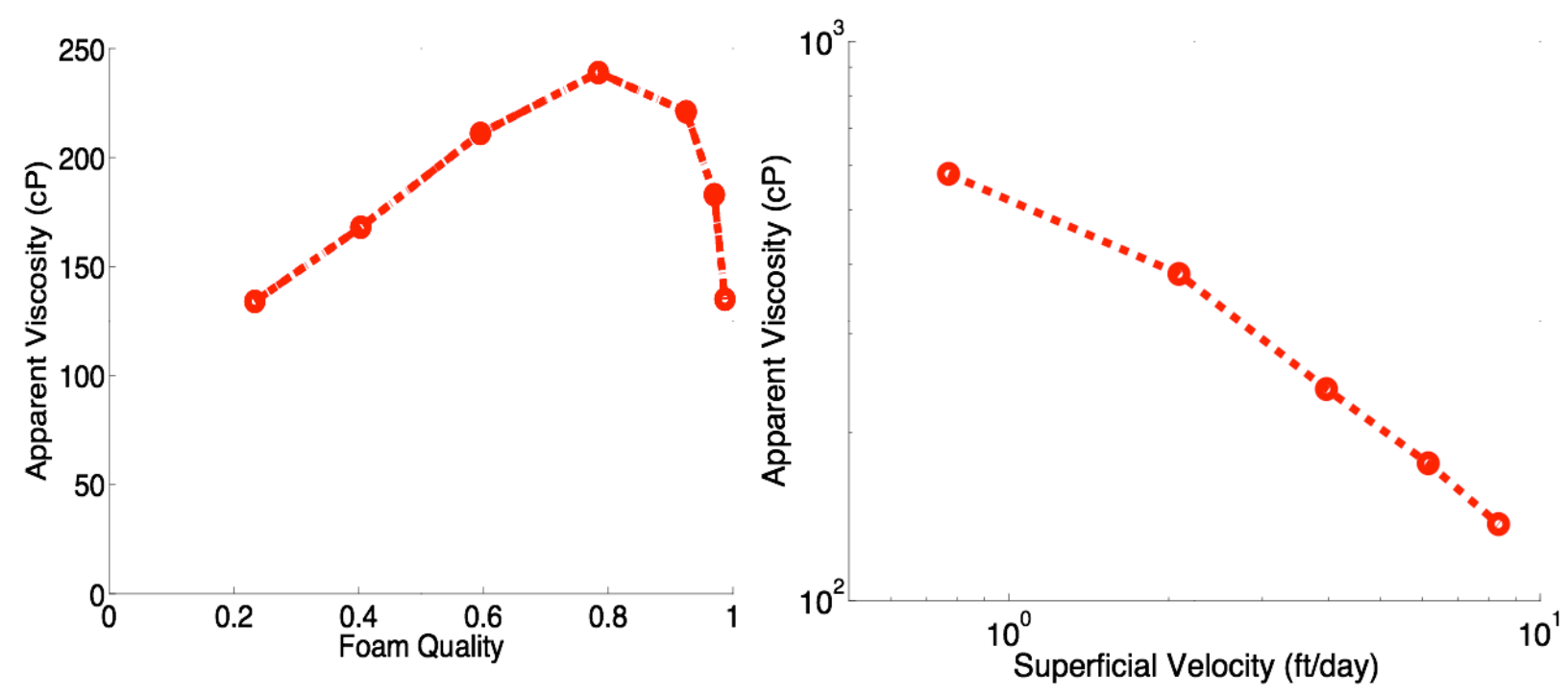

Figure 2: System A: $\mathrm{N}_{2}$ and surfactant solutions were co-injected into a 6.7-inch Bentheimer sandstone (0.65 Darcy) core at ambient temperature. A quality-scan experiment at a fixed flow rate of $4.2 \mathrm{ft} /$ day is on the left, and a flow-rate-scan experiment with a fixed foam quality of 0.78 is on the right.

The general behavior in the quality-scan experiment (Figure 2, left) indicates that the foam apparent viscosity first increased with increasing foam quality. The viscosity reached a maximum and then decreased as the quality was further increased. The decrease in apparent viscosity results from the foam dry-out effect discussed earlier. The foam apparent viscosity decreased with increasing total flow rate in the flow-ratescan experiment (Figure 2, right). Foam showed a shear-thinning behavior in System A.

\subsection{Numerical Method for the Estimation of Parameters in the $F_{\text {water }}$ Function}

Estimations of the parameters in $F_{\text {water }}$ are discussed next. $F_{\text {shear }}$ is ignored because the total flow rate was held constant in the quality-scan experiment. 
For any given pair of steady-state foam data $\left(f_{g}^{e x p}, \mu_{a p p}^{e x p}\right)$, we can solve for corresponding $S_{w}$ and $F M$ values, as shown in Equations 13 and 14. The derivation is included in the Supporting Information.

$$
\begin{array}{r}
S_{w}=\left(\frac{\mu_{w} \times\left(1-f_{g}\right)}{\mu_{a p p} \times k_{r w}^{o}}\right)^{\frac{1}{n_{w}}}\left(1-S_{w c}-S_{g r}\right)+S_{w c} \\
F M=\frac{f_{g} \times \mu_{g}}{\mu_{a p p} \times k_{r g}^{o} \times\left(\frac{1-S_{w}-S_{g r}}{1-S_{w c}-S_{g r}}\right)^{n_{g}}}
\end{array}
$$

Equation 14

For a given value of $f m m o b$, the other two parameters epdry and fmdry can be uniquely determined by a linear regression between $\tan \left(\left(\frac{(1 / F M)-1}{f m m o b}-0.5\right) \pi\right)$ and $S_{w}$. The linear relation between $\tan \left(\left(\frac{(1 / F M)-1}{f m m o b}-0.5\right) \pi\right)$ and $S_{w}$ can be derived by combining and rearranging Equations 5 and 6, as shown in Equation 15. Therefore, the three-parameter estimation ( $f m m o b, e p d r y, f m d r y)$ can be converted to optimizing a single variable $f m m o b$ that fits experimental data.

$\tan \left(\left(\frac{(1 / F M)-1}{f m m o b}-0.5\right) \pi\right)=\operatorname{epdry}\left(S_{w}-f m d r y\right)$

Equation 15

The objective function of our parameter optimization as shown in Equation 16 is to identify which $f m m o b$ value provides the optimal fit to experimental data. The first term in yellow is the normalized residual sum of squares deviation. The 
variable $\mu_{a p p, i}^{\text {exp }}$ is the $\mathrm{i}^{\text {th }}$ experiment data and $\mu_{a p p, i}^{S T A R S}$ is the model prediction, given the same foam quality and superficial velocity conditions. The variable $\mu_{a p p, \text { imax }}^{\exp }$ is the maximal foam apparent viscosity encountered in quality-scan experiment and is used for normalization of the error between experiment and modeling. The second term in blue is a penalty function that regulates the calculated transition quality $f_{g, \text { transition }}^{S T A R S}$ to be within the interval of the two neighboring points $f_{g, \text { imax }-1}^{\text {exp }}$ and $f_{g, \text { imax }+1}^{\text {exp }}$. The subscript imax refers to maximum point in experiment where the strongest foam is observed at the foam quality of $f_{g \text {, imax }}^{\text {exp }}$. Hence, we require the model to predict the foam quality transition between the low-quality and highquality regimes and it must exist within the interval $\left(f_{g, \text { imax }-1}^{\text {exp }}, f_{g, \text { imax }+1}^{\text {exp }}\right)$, as shown in Figure 3.

$\min f(f m m o b)=\left\{\frac{1}{n} \sum_{i=1}^{n}\left(\frac{\mu_{a p p, i}^{\text {exp }}-\mu_{a p p, i}^{\text {STARS }}}{\mu_{a p p, \text { imax }}^{\text {exp }}}\right)^{2}+P \times\left(\frac{f_{g, \text { imax }}^{\text {exp }}-f_{g, \text { transition }}^{\text {STARS }}}{f_{g, \text { imax }}^{\text {exp }}}\right)^{2}\right\}$

\section{P}

$=\left\{\begin{array}{cc}0 & f_{g, \text { imax }-1}^{\text {exp }}<f_{g, \text { transition }}^{\text {STARS }}<f_{g, \text { imax }+1}^{\text {exp }} \\ 1 & f_{g, \text { transition }}^{\text {STARS }}<f_{g, \text { imax }-1}^{\text {exp }} \text { or } f_{g, \text { transition }}^{\text {STARS }}>f_{g, \text { imax }+1}^{\text {exp }}\end{array}\right.$ 


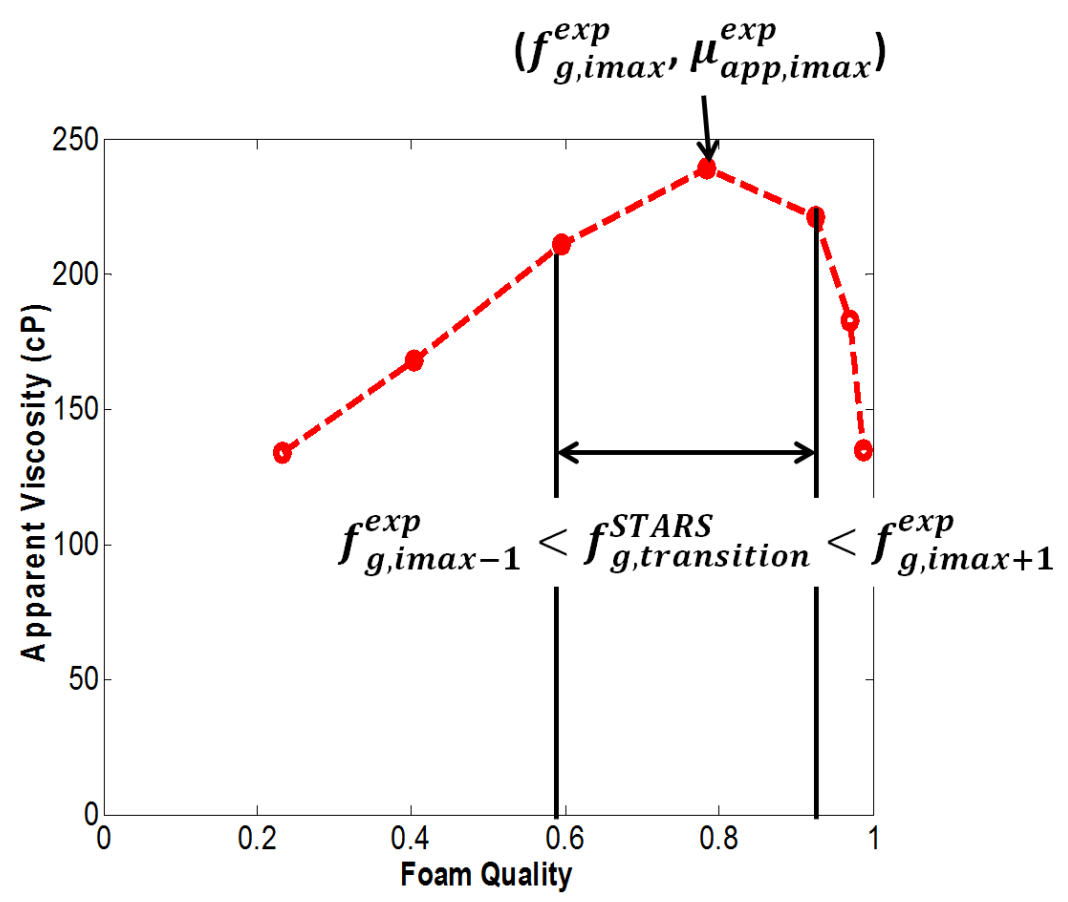

Figure 3: Quality-scan experiment for System A: the transition quality must fall within the interval of $\left(f_{g, \text { imax }-1}^{\text {exp }}, f_{g, \text { imax }+1}^{\text {exp }}\right)$

The flowchart of our proposed method to search for $f m m o b$ is shown in Figure 4. The largest $f m m o b$ observed in experiments is the upper bound given that $F_{\text {water }}$ should nearly equal 1 in the low-quality regime, where the water saturation is high. There are a number of numerical methods that can solve this constrained extremevalue problem, such as Newton's method, Bisection's method, Golden section search and simplex algorithm, etc. We simply plot the objective function in Figure 5, from which we can easily identify the global optimal value of $f m m o b$. The optimal of $f(f m m o b)$ for our demonstration System $\mathrm{A}$ is 9551.8. The linear regression between $\tan \left(\left(\frac{(1 / F M)-1}{f m m o b}-0.5\right) \pi\right)$ and $S_{w}$ is shown in Figure 6. The values of 
fmmob, epdry and fmdry are listed in Table 2, and the final data fit for the quality-scan experiment is shown in Figure 7.

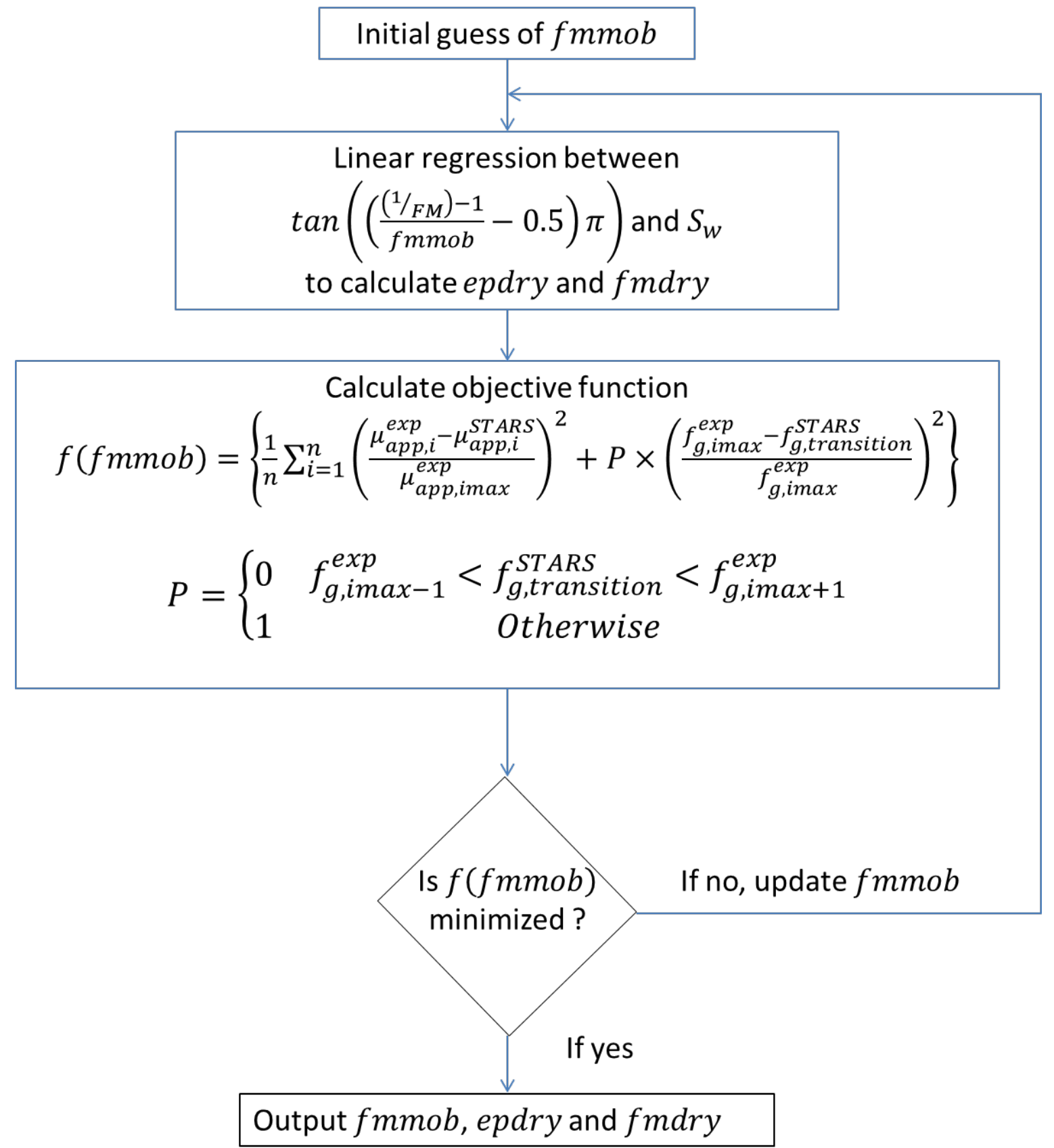

Figure 4: Flowchart outlining numerical scheme used for the estimation of fmmob, epdry, and fmdry 


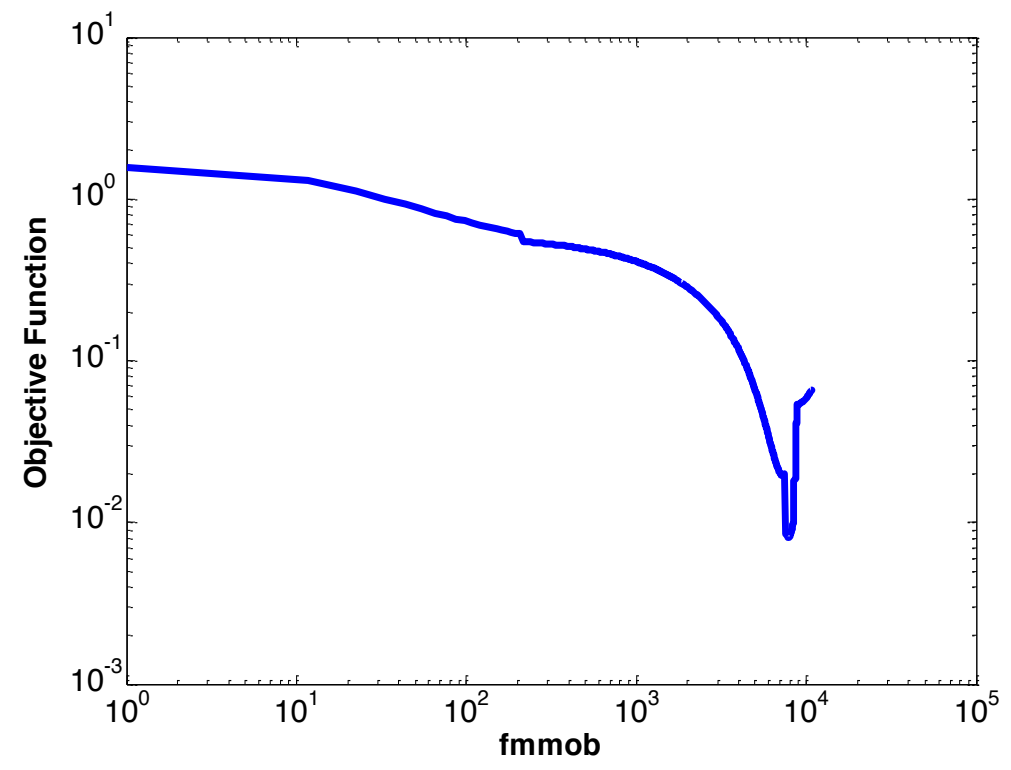

Figure 5: The objective function $f(f m m o b)$ vs. fmmob

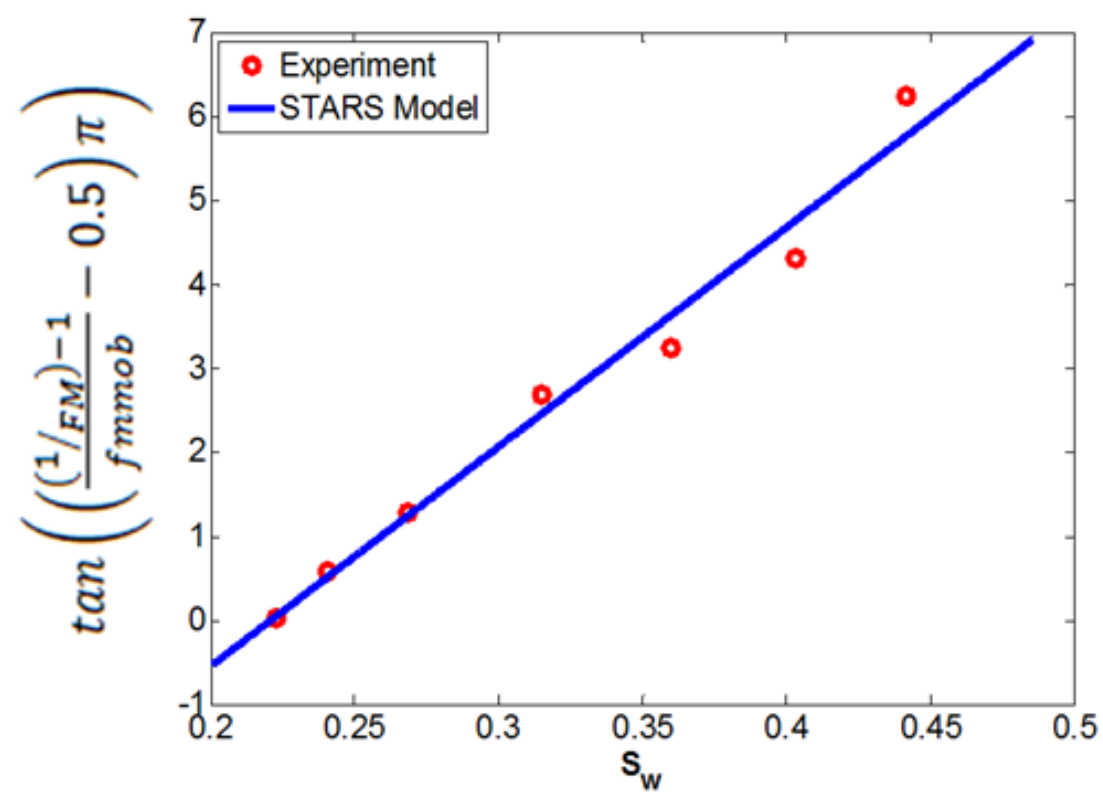

Figure 6: The linear regression between $\tan \left(\left(\frac{(1 / F M)-1}{f m m o b}-0.5\right) \pi\right)$ and $S_{w}$ 
Table 2: Quality-scan experimental data fit to the STARS ${ }^{\mathrm{TM}}$ model

\begin{tabular}{|c|c|c|}
\hline fmmob & epdry & fmdry \\
\hline 9551.8 & 26.1374 & 0.22 \\
\hline
\end{tabular}

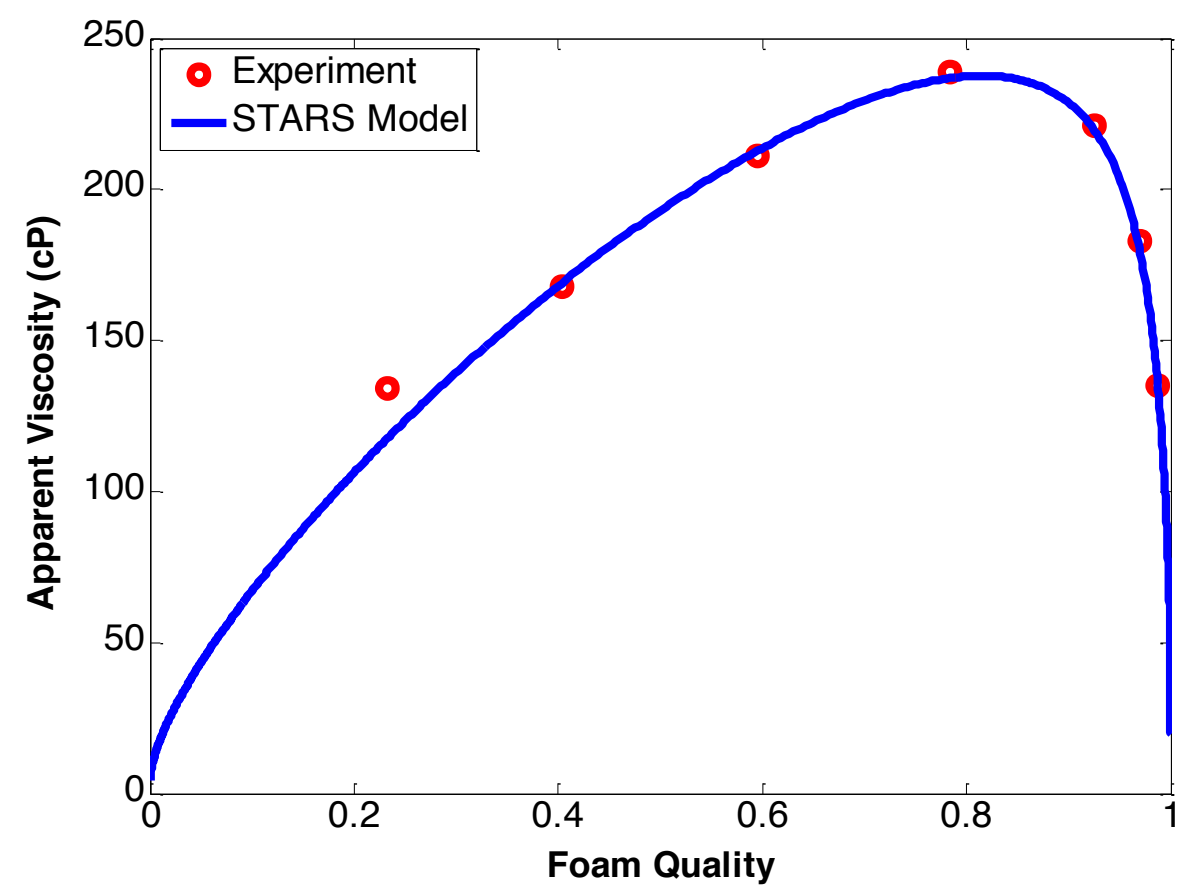

Figure 7: Quality-scan experimental data fit to the STARS ${ }^{\mathrm{TM}}$ model

\subsection{Estimation of Parameters in $\boldsymbol{F}_{\text {shear }}$ Function}

The two parameters epcap and fmcap in $F_{\text {shear }}$ will be estimated from the flowrate-scan experiments. We combine Equations 5-7 and rearrange such that a linear regression is applied to compute epcap and fmcap. Given viscosity $\mu$ and surface tension $\sigma$, we can conduct a linear regression between $\log _{10}\left(\frac{(1 / F M)-1}{f m m o b \times F_{\text {water }}}\right)$ and 
$\log _{10}\left(N_{C a}\right)$, as shown in Equation 17. The data fit results are shown in Figure 8. The parameter epcap is regressed to be 26.1 and fmcap to be 0.22 .

$$
\log _{10}\left(\frac{(1 / F M)-1}{f m m o b \times F_{\text {water }}}\right)=-e p c a p \times\left(\log _{10}\left(N_{C a}\right)+\log _{10}(\text { fmcap })\right)
$$
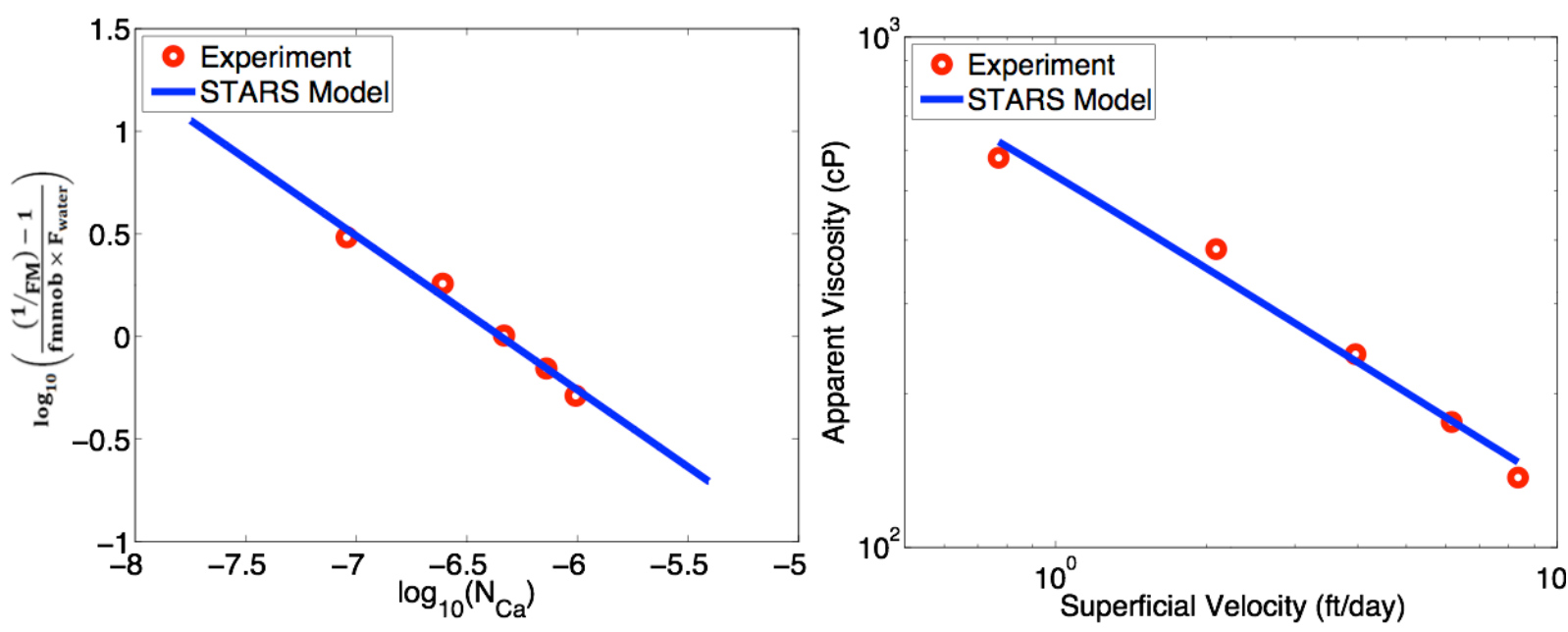

Figure 8: Flow-rate-scan experimental data fit to $\mathrm{STARS}^{\mathrm{TM}}$ model

\subsection{Other Foam Systems}

We have demonstrated how to fit the five parameters from the quality-scan and the flow-rate-scan foam flood experiments for the STARS ${ }^{\mathrm{TM}}$ model. Next, we will apply this method to a variety of systems to validate robustness and establish interpretations from the data.

\subsubsection{System B: Effect of Gas Type: $\mathrm{N}_{2}, \mathrm{CH}_{4}$ and $\mathrm{CO}_{2}$ Foams}


We investigate the effect of gas type on steady-state foam strength in porous media in System B. Three types of gases were co-injected with a $1 \mathrm{wt} \%$ AOS1416 surfactant solution into the Bentheimer sandstone core. It should be noted that the aqueous solution was pre-saturated with $\mathrm{CO}_{2}$ because of the relatively high solubility of $\mathrm{CO}_{2}$ in water. The experimental data and the STARS $^{\mathrm{TM}}$ model fits are shown in Table 3 and Figure 9, respectively. Only quality-scan experiments were completed, and therefore data to fit epcap and fmcap in $F_{\text {shear }}$ were unavailable. Our algorithm works well with this system and provides a satisfactory fit to the experimental data. We find that the nitrogen $\left(\mathrm{N}_{2}\right)$ foam is always the strongest, whereas the carbon dioxide $\left(\mathrm{CO}_{2}\right)$ foam is the weakest. The methane $\left(\mathrm{CH}_{4}\right)$ foam produced the intermediate foam strength for a given foam quality.

Table 3: STARS ${ }^{\mathrm{TM}}$ model parameters fitted for experiments with different types of gas

\begin{tabular}{|c|c|c|c|}
\hline Gas Type & fmmob & epdry & fmdry \\
\hline $\mathrm{N}_{2}$ & $5.1 \mathrm{e}+4$ & 412.0 & 0.20 \\
\hline $\mathrm{CH}_{4}$ & $3.5 \mathrm{e}+4$ & 74.2 & 0.22 \\
\hline $\mathrm{CO}_{2}$ & $2.8 \mathrm{e}+4$ & 24.1 & 0.25 \\
\hline
\end{tabular}




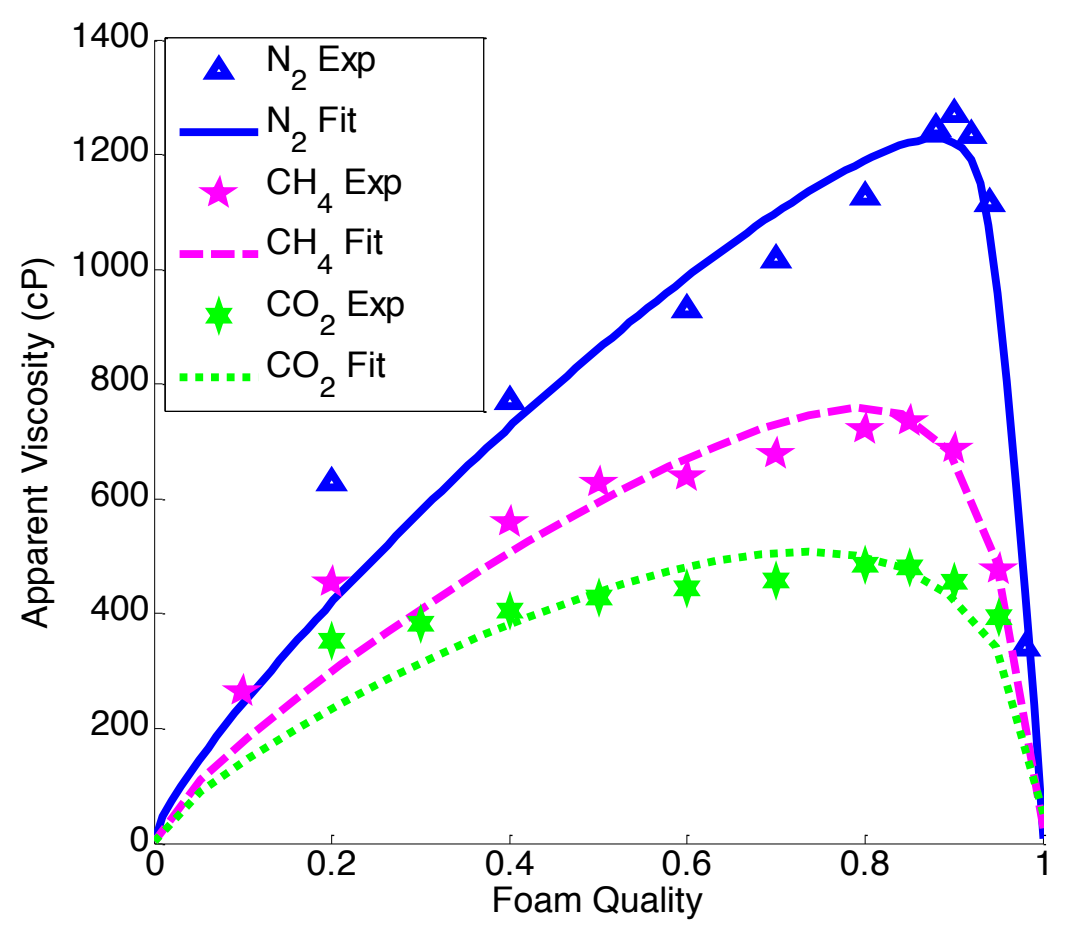

Figure 9: Data fit to STARS ${ }^{\mathrm{TM}}$ model for different gas type experiments

We calculate the corresponding limiting capillary pressure based on fmdry values in Table 3 to estimate the flowing foam film stability for foams of different gas types. We use the Leverett $\mathrm{J}$ function for Bentheimer sandstone ${ }^{47}$, to estimate the limiting capillary pressure $P_{c}^{*}$ as shown in Equation 18, in which $\sigma$ is surface tension and $\phi$ is porosity.

$$
P_{c}^{*}=J\left(S_{w}^{*}\right) \cdot \sigma \cdot \sqrt{\frac{\phi}{k_{\text {rock }}}}=J(f m d r y) \cdot \sigma \cdot \sqrt{\frac{\phi}{k_{\text {rock }}}}
$$


If we use the transition foam apparent viscosity as a measure of the maximum foamability for the $\mathrm{N}_{2}, \mathrm{CH}_{4}$ and $\mathrm{CO}_{2}$ foams, we show in Figure 10 that the transition foam strength for different gas types is correlated significantly with limiting capillary pressure. $\mathrm{N}_{2}$ has the largest $P_{c}^{*}$ value and thus produces the strongest foam, whereas $\mathrm{CO}_{2}$ has the weakest $P_{c}^{*}$ value and thus produces the weakest foam. Consequently, we assume that the limiting capillary pressure is a good indicator of foam strength in porous media.

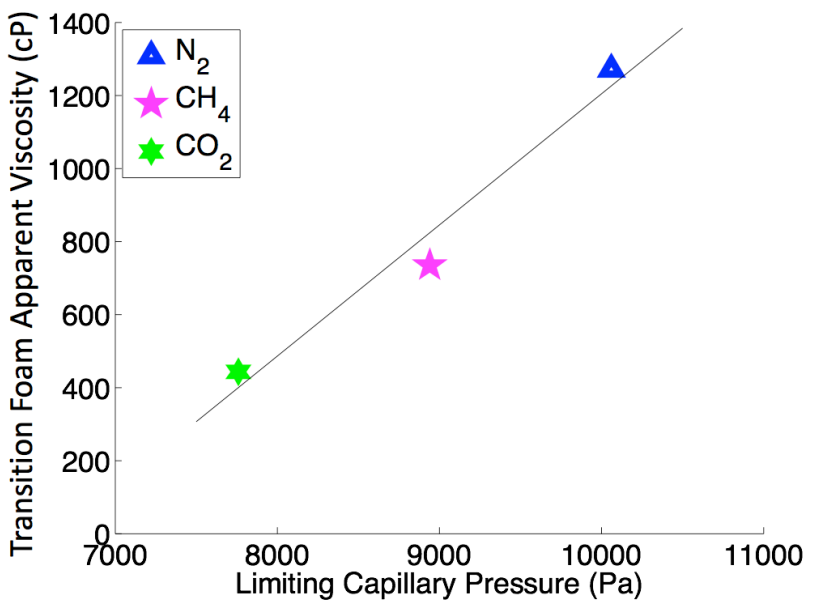

Figure 10: Transition foam strength for different gas types as a function of limiting capillary pressure estimated from $\boldsymbol{f m d r y}$.

\subsubsection{System C: Anionic surfactant foam (AOS1416) vs. zwitterionic surfactant foams (LB and LS)}

We compare the anionic surfactant AOS1416 with two different Zwitterionic surfactants, LB and LS, in terms of steady-state foam strength in porous media in System C. $0.5 \mathrm{wt} \%$ of AOS 1416, LB and LS were co-injected 
with $\mathrm{N}_{2}$. Applying the same algorithm as described in Sections 4.1 and 4.2, we can fit the experimental data to the STARS ${ }^{\mathrm{TM}}$ model, as shown in Table 4 and Figure 11. As demonstrated, our algorithm provides a good fit to all three foam systems, although their general trends are quite different.

Table 4: STARS ${ }^{\mathrm{TM}}$ model parameters fitted for experiments with two different zwitterionic surfactants

\begin{tabular}{|c|c|c|c|c|c|}
\hline Surfactant & fmmob & epdry & fmdry & epcap & fmcap \\
\hline LS & $1.9 \mathrm{e}+6$ & 233.0 & 0.34 & 1.276 & $6.4 \mathrm{e}-08$ \\
\hline LB & $1.4 \mathrm{e}+5$ & 43.9 & 0.29 & 1.284 & $3.3 \mathrm{e}-07$ \\
\hline AOS416 & $7.7 \mathrm{e}+4$ & 825.8 & 0.22 & 0.428 & $1.5 \mathrm{e}-07$ \\
\hline
\end{tabular}
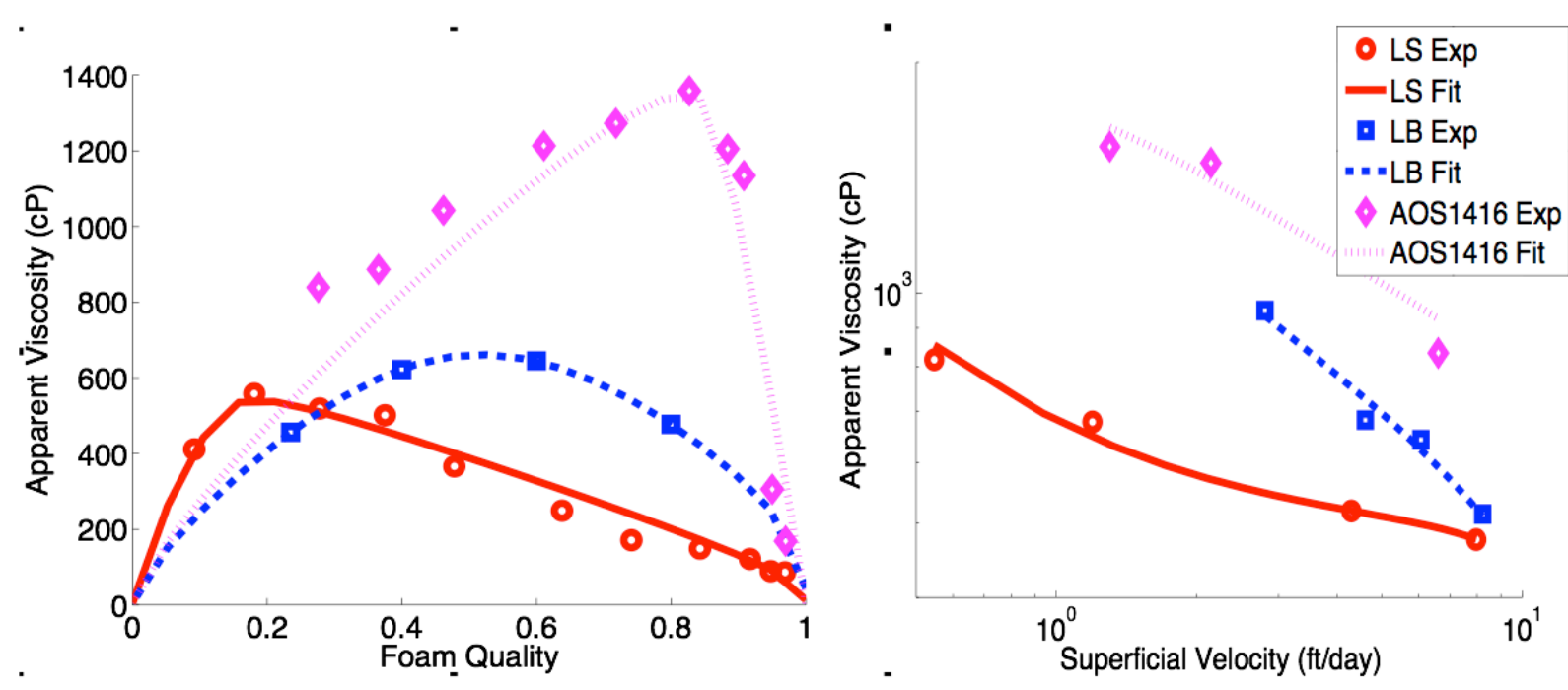

Figure 11: Experimental data and STARS ${ }^{\mathrm{TM}}$ model fit for $0.5 \mathrm{wt} \%$ AOS1416, LB and LS foams. 
Figure 11 illustrates that AOS1416 is a more effective foamer in terms of apparent viscosity for both the quality and flow-rate-scans compared to zwitterionic surfactants, such as LB and LS. Surface tension $\sigma$ is needed for different surfactant solutions against air to estimate the flowing foam film stability for different surfactant types. The $\sigma$ was measured in our experiment using Kibron-EZ Pi plus (Kibron Inc., Helsinki, Finland) based on the DuNouy Padday principle. The results are shown in Figure 12.

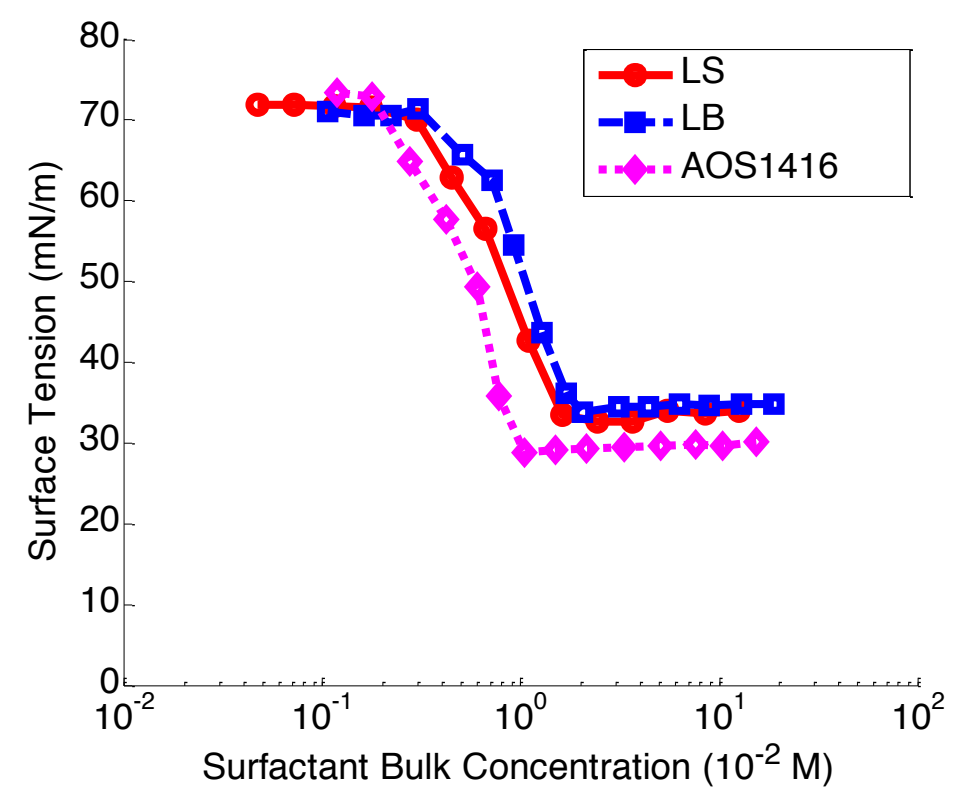

Figure 12: Surface tension measurement for different surfactant types (AOS1416, LB and LS) 
We apply the same method to calculate the limiting capillary pressure $P_{c}^{*}$ to evaluate the foam film stability for different surfactant types, as shown in Table 5 .

Table 5: Limiting capillary pressure for foams with different surfactants types (AOS1416, LB, LS)

\begin{tabular}{|c|c|c|c|c|}
\hline Surfactant & $\begin{array}{c}\text { Concentration } \\
(\mathrm{wt} \%)\end{array}$ & $\begin{array}{c}\text { Surface tension } \sigma \\
(\mathrm{mN} / \mathrm{m})\end{array}$ & fmdry & $\begin{array}{c}P_{c}^{*} \\
(\mathrm{kPa})\end{array}$ \\
\hline AOS1416 & 0.5 & 29.7 & 0.22 & 8.2 \\
\hline LB & 0.5 & 34.7 & 0.29 & 7.2 \\
\hline LS & 0.5 & 33.4 & 0.34 & 5.8 \\
\hline
\end{tabular}

The limiting capillary pressure values correlate with the transition foam strengths for the foam of three different surfactants. The AOS1416 foam shows the highest limiting capillary pressure $P_{c}^{*}$ and the strongest foam strength, whereas the LS foam shows the lowest $P_{c}^{*}$ and the weakest foam strength. We calculate the Gibbs surface excess $\Gamma^{s}$ as shown in Equation 19 ${ }^{48,49}$ to estimate the packing of surfactant molecules onto the gas-liquid interface to understand the underlying mechanism that explains the difference in foam strength for different surfactant types. The $a$ is the surfactant activity, $a_{t}$ is the total activity of both surfactant and inorganic salts, $R$ is the gas constant, and $T$ is temperature. 


$$
\Gamma^{s}=\frac{1}{R T} \frac{d \sigma}{d \ln \left(a a_{t}\right)}
$$

Equation 19

The Pitzer model ${ }^{50}$ was used to calculate the activity coefficients to account for the interactions between all inorganic salts and surfactant molecules. Derivation details and the interaction parameters can be found in the literature 48,50,51. The Gibbs surface excess as a function of surfactant concentration is shown in Figure 13. AOS1416 has a higher surface excess concentration compared to both zwitterionic surfactants LB and LS. The different chemical structures of AOS1416 and LB/LS may explain their different foaming capability in porous media. As for the hydrophobic tails, surfactants with a longer hydrocarbon tail are more likely to be better foaming agents. Svorstoel et al. $^{8}$ did an experiment on AOS with a series of different tail groups and found out that AOS16 is better than AOS1416 and both are better than AOS14 in foaming in porous media. In our experiment, AOS1416 has a longer hydrocarbon tail (C14 and C16) compared to LB/LS (C12 and C14). Besides the difference in tails, the head group repulsions between AOS molecules are very sensitive to salinity ${ }^{48}$ and the electrostatic repulsion can be screened by the counter-ions, such as $\mathrm{Na}^{+}, \mathrm{Ca}^{2+}$, and $\mathrm{Mg}^{2+}$ in the diffuse layer, which aide AOS1416, to pack tightly on the interface and create more stable foam films. However, the head group of zwitterionic surfactants is a permanent dipole moment which has zero net charge and thusly less sensitive to salinity ${ }^{52,53}$. Thus the concentration of counter-ions will have less effect on the interface with zwitterionic surfactants. 


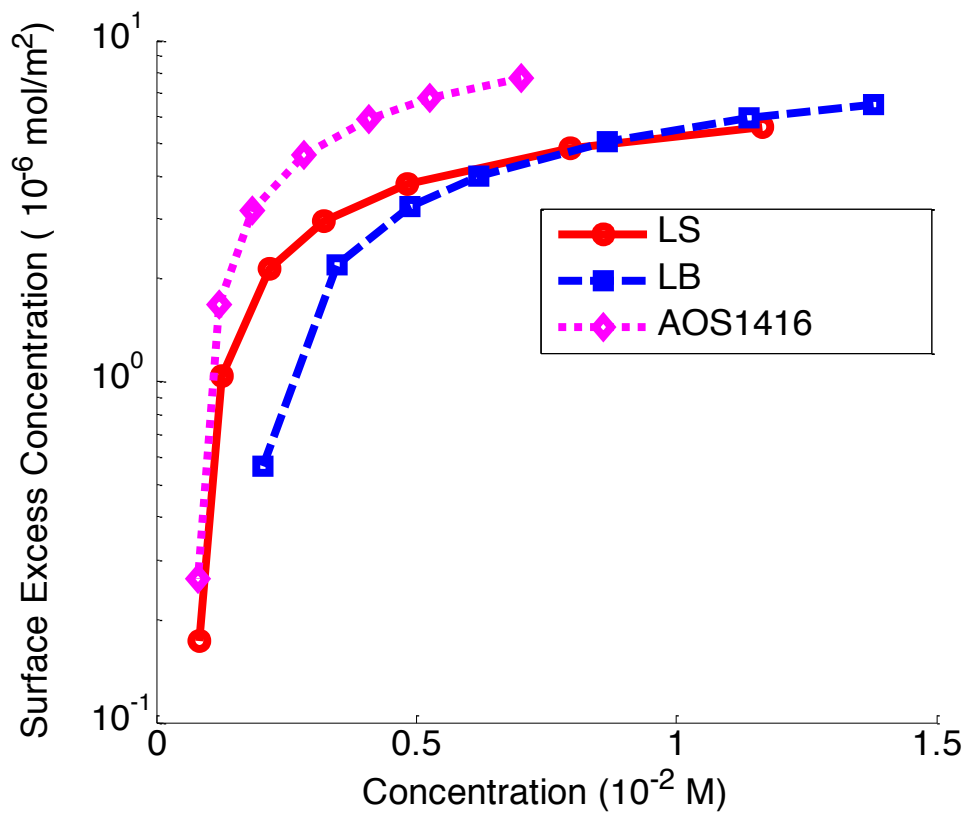

Figure 13: Gibbs surface excess adsorption on air-water interface for different surfactant types

\section{Conclusions}

In summary, we propose an improved algorithm to estimate the STARS ${ }^{\mathrm{TM}}$ foam model parameters. The algorithm reduces the five-parameter estimation to a few simpler steps, such as linear regression and single-variable optimization, and avoids sensitivities of initial estimates and non-uniqueness solution issues. We also compare our improved algorithm with others reported in literature. The robustness of the algorithm has been validated by varied foam systems. We find that the limiting capillary pressure is a good 
indicator of film stability for flowing foam in porous media. We also realize that the anionic surfactant AOS1416 is a more effective foamer compared to zwitterionic surfactants LB/LS. The Gibbs excess adsorption is calculated to explain the difference in foamability of different surfactant types. Other future work includes (1) assessing the accuracy of our algorithm from flow-rate-scan data for other foam qualities and (2) extending the algorithm to estimate the parameters in other dependent functions.

\section{Acknowledgements}

We acknowledge the financial and technical support from the Rice University Consortium for Processes in Porous Media (Houston, TX, USA), Delft University of Technology (Delft, the Netherlands) and Shell Global Solutions International (Rijswijk, the Netherlands). We thank Professor Clarence A. Miller from Rice University for insightful discussions. Ing. M. (Michiel) Slob is gratefully acknowledged for his technical support of lab setup. 


\section{Nomenclature}

\begin{tabular}{|c|c|}
\hline$a$ & Surfactant activity \\
\hline$a_{t}$ & Total activity of surfactant and salts \\
\hline epdry & Foam model parameter in $F_{\text {Water }}$ \\
\hline epsurf & Foam model parameter in $F_{\text {Shear }}$ \\
\hline$f_{g}$ & Foam quality (Gas fractional flow) \\
\hline$F M$ & Mobility reduction factor \\
\hline fmdry & Foam model parameter in $F_{\text {Water }}$ \\
\hline fmmob & Reference to the maximum gas mobility reduction that can be achieved \\
\hline fmsurf & Foam model parameter in $F_{\text {Shear }}$ \\
\hline$J$ & Leverett $\mathrm{J}$ function \\
\hline$k_{\text {rock }}$ & Rock permeability \\
\hline$k_{r g}^{f}$ & Relative permeability of gas phase in the state of foam \\
\hline$k_{r g}^{n f}$ & Relative permeability of gas phase in absence of foam \\
\hline$k_{r g}^{o}$ & End-point relative permeability of gas phase \\
\hline$k_{r w}$ & Relative permeability of water phase \\
\hline$k_{r w}^{o}$ & End-point relative permeability of water phase \\
\hline$L$ & Length of 1-D formation \\
\hline$n_{g}$ & Corey exponent for gas phase \\
\hline$n_{w}$ & Corey exponent for water phase \\
\hline$p$ & Pressure \\
\hline$P_{c}$ & Capillary pressure \\
\hline$P_{c}^{*}$ & Limiting capillary pressure \\
\hline$R$ & Gas constant \\
\hline$S_{g r}$ & Residual gas saturation \\
\hline$S_{w}$ & Water saturation \\
\hline$S_{w r}$ & Residual water saturation \\
\hline$T$ & Temperature \\
\hline$u_{g}$ & Superficial velocity of gas phase \\
\hline$u_{t}$ & Total superficial velocity \\
\hline$u_{w}$ & Superficial velocity of water phase \\
\hline$\Gamma^{s}$ & Surface excess concentration of surfactant \\
\hline$\sigma$ & Surface tension \\
\hline$\phi$ & Porosity \\
\hline$\mu_{a p p}$ & Apparent Viscosity of foam \\
\hline$\mu_{g}$ & Viscosity of gas \\
\hline$\mu_{w}$ & Viscosity of water \\
\hline
\end{tabular}




\section{References}

(1) Falls, A.; Hirasaki, G.; Patzek, T. e al; Gauglitz, D.; Miller, D.; Ratulowski, T. Development of a Mechanistic Foam Simulator: The Population Balance and Generation by Snap-Off. SPE Reserv. Eng. 1988, 3 (03), 884.

(2) Hirasaki, G. J.; Miller, C. A.; Szafranski, R.; Lawson, J. B.; Akiya, N. Surfactant/Foam Process for Aquifer Remediation; Society of Petroleum Engineers (SPE SPE-37257-MS), Houston, Texas, 1997.

(3) Blaker, T.; Aarra, M. G.; Skauge, A.; Rasmussen, L.; Celius, H. K.; Martinsen, H. A.; Vassenden, F. Foam for Gas Mobility Control in the Snorre Field: The FAWAG Project. SPE Reserv. Eval. Eng. 2002, 5 (04), 317.

(4) Chen, Y.; Elhag, A. S.; Cui, L.; Worthen, A. J.; Reddy, P. P.; Noguera, J. A.; Ou, A. M.; Ma, K.; Puerto, M.; Hirasaki, G. J.; et al. CO2 -in-Water Foam at Elevated Temperature and Salinity Stabilized with a Nonionic Surfactant with a High Degree of Ethoxylation. Ind. Eng. Chem. Res. 2015, 54 (16), 4252.

(5) Chen, Y.; Elhag, A. S.; Poon, B. M.; Cui, L.; Ma, K.; Liao, S. Y.; Reddy, P. P.; Worthen, A. J.; Hirasaki, G. J.; Nguyen, Q. P.; et al. Switchable Nonionic to Cationic Ethoxylated Amine Surfactants for CO2 Enhanced Oil Recovery in High-Temperature, High-Salinity Carbonate Reservoirs. SPE J. 2014, 19 (02), 249.

(6) Cui, L.; Ma, K.; Puerto, M.; Abdala, A. A.; Tanakov, I.; Lu, L. J.; Chen, Y.; Elhag, A.; Johnston, K. P.; Biswal, S. L.; et al. Mobility of Ethomeen C12 and Carbon Dioxide Foam at High Temperature/High Salinity and in Carbonate Cores. SPE J. 2016.

(7) Spirov, P.; Rudyk, S.; Khan, A. Foam Assisted WAG, Snorre Revisit with New Foam Screening Model; Society of Petroleum Engineers: (SPE 150829-MS), Cairo, Egypt, 2012.

(8) Svorstoel, I.; Blaker, T.; Arneson, S.; Holt, T.; Vassenden, F.; M. Surguchev, L. Foam Pilot Evaluations for the Snorre Field, Part 1: Project and Laboratory Results; 1995, SPE $8^{\text {th }}$ European IOR Symposium, Vienna Australia.

(9) Gaydos, J. S.; Harris, P. C. Foam Fracturing: Theories, Procedures And Results; Society of Petroleum Engineers (SPE-8961), 1980, Pittsburgh, Pennsylvania.

(10) Harris, P. C.; Pippin, M. High-Rate Foam Fracturing; Society of Petroleum Engineers (39959-MS SPE), 1998, Denver Colorado.

(11) McAndrew, J. J.; Fan, R.; Sharma, M.; Ribeiro, L. Extending the Application of Foam Hydraulic Fracturing Fluids; American Association of Petroleum Geologists (2014-1926561-MS), 2014, Denvor, Colorado.

(12) Boeije, C. S.; Rossen, W. Fitting Foam-Simulation-Model Parameters to Data: I. Coinjection of Gas and Liquid. SPE Reserv. Eval. Eng. 2015, 18 (02), 264.

(13) Cheng, L.; Reme, A.; Shan, D.; Coombe, D.; Rossen, W. Simulating Foam Processes at High and Low Foam Qualities (59287-MS SPE); Society of Petroleum Engineers: Tulsa, Oklahoma, 2000.

(14) Lake, L.; Johns, R.; Rossen, W. R.; Pope, G. Fundementals of Enhanced Oil Recovery; Society of Petroleum Engineers, 2014.

(15) Rossen, W. R. Theories of Foam Mobilization Pressure Gradient. In SPE-17358-MS; Society of Petroleum Engineers: SPE, 1988.

(16) Harpole, K. J.; Siemers, W. T.; Gerard, M. G. CO2 Foam Field Verification Pilot Test at EVGSAU: Phase IIIC--Reservoir Characterization and Response to Foam Injection; Society of Petroleum Engineers (27798-MS SPE), 1994, Tulsa, Oklahoma.

(17) Martin, F. D.; Heller, J. P.; Weiss, W. W.; Tsau, J.-S.; Zornes, D. R.; Sugg, L. A.; Stevens, J. E.; Kim, J. E. CO2-Foam Field Verification Pilot Test at EVGSAU Injection Project Phase I: Project 
Planning and Initial Results; Society of Petroleum Engineers (24176-MS SPE), 1992, Tulsa, Oklahoma.

(18) Stevens, J. E. CO2 Foam Field Verification Pilot Test at EVGSAU: Phase IIIB--Project Operations and Performance Review. SPE Reserv. Eng. 1995, 10 (04), 266.

(19) Stevens, J. E.; Harpole, K. J.; Zornes, D. R.; Martin, F. D. CO2 Foam Field Verification Pilot Test at EVGSAU: Phase II - Foam Injection Design and Operating Plan; Society of Petroleum Engineers (SPE-24642-MS), 1992, Washington, D.C.

(20) Tsau, J.-S.; Heller, J. P. CO2 Foam Field Verification Pilot Test at EVGSAU: Phase IIIA-Surfactant Performance Characterization and Quality Assurance; Society of Petroleum Engineers, (SPE-27785-MS), 1994, Tulsa, Oklahoma.

(21) Ma, K.; Ren, G.; Mateen, K.; Morel, D.; Cordelier, P. Modeling Techniques for Foam Flow in Porous Media. SPE J. 2015, 20 (03), 453.

(22) Rossen, W. R. Numerical Challenges in Foam Simulation: A Review; Society of Petroleum Engineers (SPE-166232-MS): New Orleans, Louisiana, USA, 2013.

(23) Kovscek, A. R.; Patzek, T. W.; Radke, C. J. A Mechanistic Population Balance Model for Transient and Steady-State Foam Flow in Boise Sandstone. Chem. Eng. Sci. 1995, 50 (23), 3783.

(24) Patzek, T. W. Modeling of Foam Flow in Porous Media by the Population Balance Method; Smith, D. H., Ed.; Surfactant-Based Mobility Control; American Chemical Society: Washington, DC, 1988; Vol. 373.

(25) Ma, K.; Lopez-Salinas, J. L.; Puerto, M. C.; Miller, C. A.; Biswal, S. L.; Hirasaki, G. J. Estimation of Parameters for the Simulation of Foam Flow through Porous Media. Part 1: The Dry-Out Effect. Energy Fuels 2013, 27 (5), 2363.

(26) Alvarez, J. M.; Rivas, H. J.; Rossen, W. R.; others. Unified Model for Steady-State Foam Behavior at High and Low Foam Qualities. SPE J. 2001, 6 (03), 325.

(27) Singh, R.; Mohanty, K. K. Synergistic Stabilization of Foams by a Mixture of Nanoparticles and Surfactants; Society of Petroleum Engineers (169126-MS SPE), 2014, Tulsa, Oklahoma.

(28) Dicksen, T.; Hirasaki, G. J.; Miller, C. A. Conditions for Foam Generation in Homogeneous Porous Media; Society of Petroleum Engineers (SPE-75176-MS): SPE, 2002, Tulsa, Oklahoma.

(29) Liontas, R.; Ma, K.; Hirasaki, G. J.; Biswal, S. L. Neighbor-Induced Bubble Pinch-off: Novel Mechanisms of in Situ Foam Generation in Microfluidic Channels. Soft Matter 2013, 9 (46), 10971.

(30) Dicksen, T.; Hirasaki, G. J.; Miller, C. A.; others. Mobility of Foam in Heterogeneous Media: Flow Parallel and Perpendicular to Stratification. SPE J. 2002, 7 (02), 203.

(31) Kovscek, A. R.; Radke, C. J. Gas Bubble Snap-off under Pressure-Driven Flow in Constricted Noncircular Capillaries. Colloids Surf. Physicochem. Eng. Asp. 1996, 117 (1-2), 55.

(32) Ransohoff, T. C.; Radke, C. J. Mechanisms of Foam Generation in Glass-Bead Packs. SPE Reserv. Eng. 1988, 3 (02), 573.

(33) Farajzadeh, R.; Vincent-Bonnieu, S.; Bourada Bourada, N. Effect of Gas Permeability and Solubility on Foam. J. Soft Matter 2014, 2014, 1.

(34) Nonnekes, L. E.; Cos, S.; Rossen, W. R. Effect of Gas Diffusion on Mobility of Foam for EOR; Society of Petroleum Engineers: SPE (SPE-159817-MS), 2012, San Antonio, Texas.

(35) Vrij, A. Possible Mechanism for the Spontaneous Rupture of Thin, Free Liquid Films. Discuss. Faraday Soc. 1966, 42, 23.

(36) Abbaszadeh, M.; Kazemi Nia Korrani, A.; Lopez-Salinas, J. L.; Rodriguez-de La Garza, F.; Villavicencio Pino, A.; Hirasaki, G. Experimentally-Based Empirical Foam Modeling; Society of Petroleum Engineers (SPE-169888-MS): Tulsa, Oklahoma, USA, 2014.

(37) Conn, C. A.; Ma, K.; Hirasaki, G. J.; Biswal, S. L. Visualizing Oil Displacement with Foam in a Microfluidic Device with Permeability Contrast. Lab Chip 2014, 14 (20), 3968.

(38) Ma, K.; Farajzadeh, R.; Lopez-Salinas, J. L.; Miller, C. A.; Biswal, S. L.; Hirasaki, G. J. NonUniqueness, Numerical Artifacts, and Parameter Sensitivity in Simulating Steady-State and Transient Foam Flow Through Porous Media. Transp. Porous Media 2014, 102 (3), 325. 
(39) Bernard, G. G.; Jacobs, W. L. Effect of Foam on Trapped Gas Saturation and on Permeability of Porous Media to Water. Soc. Pet. Eng. J. 1965, 5 (04), 295.

(40) Khatib, Z. I.; Hirasaki, G. J.; Falls, A. H. Effects of Capillary Pressure on Coalescence and Phase Mobilities in Foams Flowing Through Porous Media. SPE Reserv. Eng. 1988, 3 (03), 919.

(41) Farajzadeh, R.; Lotfollahi, M.; Eftekhari, A. A.; Rossen, W. R.; Hirasaki, G. J. H. Effect of Permeability on Implicit-Texture Foam Model Parameters and the Limiting Capillary Pressure. Energy Fuels 2015, 29 (5), 3011.

(42) Lee, W.; Lee, S.; Kam, S. I. Dimensionality-Dependent Foam Rheological Properties: How to Go From Linear to Radial Geometry for Foam Modeling and Simulation?; Society of Petroleum Engineers (175015-MS SPE), 2015, Houston, Texas.

(43) Bretherton, F. P. The Motion of Long Bubbles in Tubes. J. Fluid Mech. 1961, 10 (02), 166.

(44) Hirasaki, G. J.; Lawson, J. B. Mechanisms of Foam Flow in Porous Media: Apparent Viscosity in Smooth Capillaries. Soc. Pet. Eng. J. 1985, 25 (02), 176.

(45) Li, R. F.; Yan, W.; Liu, S.; Hirasaki, G.; Miller, C. A. Foam Mobility Control for Surfactant Enhanced Oil Recovery. SPE J. 2010, 15 (04), 928.

(46) Burdine, N. T. Relative Permeability Calculations From Pore Size Distribution Data. J. Pet. Technol. 1953, 5 (03), 71.

(47) Oren, P.-E.; Bakke, S.; Arntzen, O. J. Extending Predictive Capabilities to Network Models. SPE J. 1998, 3 (04), 324.

(48) Farajzadeh, R.; Krastev, R.; Zitha, P. L. J. Foam Films Stabilized with Alpha Olefin Sulfonate (AOS). Colloids Surf. Physicochem. Eng. Asp. 2008, 324 (1-3), 35.

(49) Gurkov, T. D.; Dimitrova, D. T.; Marinova, K. G.; Bilke-Crause, C.; Gerber, C.; Ivanov, I. B. Ionic Surfactants on Fluid Interfaces: Determination of the Adsorption; Role of the Salt and the Type of the Hydrophobic Phase. Colloids Surf. Physicochem. Eng. Asp. 2005, 261 (1-3), 29.

(50) Pitzer, K. S.; Mayorga, G. Thermodynamics of Electrolytes. II. Activity and Osmotic Coefficients for Strong Electrolytes with One or Both Ions Univalent. J. Phys. Chem. 1973, 77 (19), 2300.

(51) Gurkov, T. D.; Dimitrova, D. T.; Marinova, K. G.; Bilke-Crause, C.; Gerber, C.; Ivanov, I. B. Ionic Surfactants on Fluid Interfaces: Determination of the Adsorption; Role of the Salt and the Type of the Hydrophobic Phase. Colloids Surf. Physicochem. Eng. Asp. 2005, 261 (1-3), 29.

(52) Chorro, M.; Kamenka, N.; Faucompre, B.; Partyka, S.; Lindheimer, M.; Zana, R. Micellization and Adsorption of a Zwitterionic Surfactant: N-Dodecyl Betaine-effect of Salt. Colloids Surf. Physicochem. Eng. Asp. 1996, 110 (3), 249.

(53) Wang, D.; Liu, C.; Wu, W.; Wang, G. Novel Surfactants That Attain Ultra-Low Interfacial Tension between Oil and High Salinity Formation Water without Adding Alkali, Salts, CoSurfactants, Alcohols and Solvents; Society of Petroleum Engineers (SPE-127452-MS), 2010, Muscat, Oman. 
TOC Abstract:

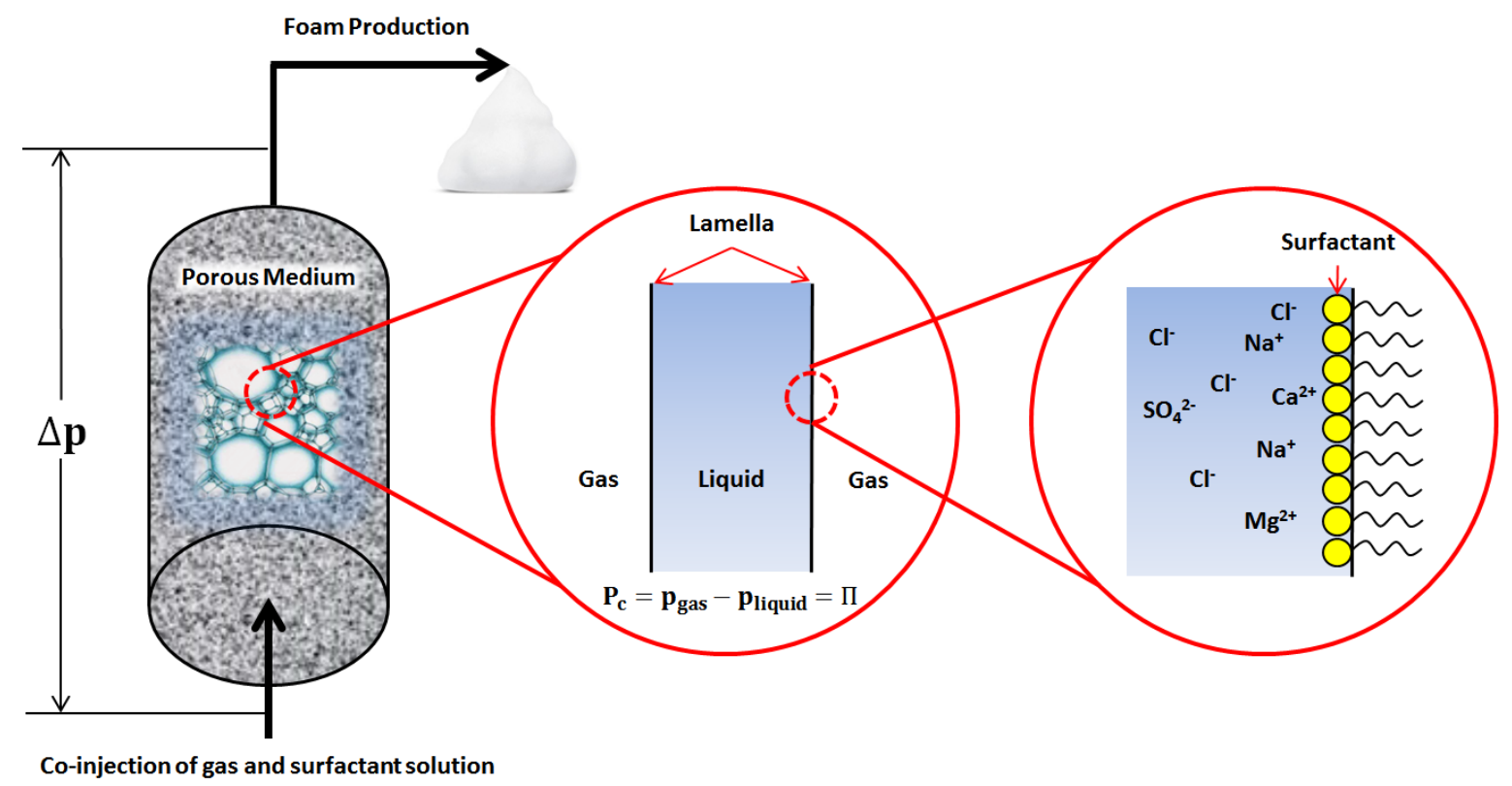

